\title{
Sabine Mohr, Clausal architecture and subject positions: Impersonal constructions in the Germanic languages
}

\author{
(Linguistik Aktuell/Linguistics Today, 88). John Benjamins, \\ Amsterdam, 2005, viii, 207 pp, ISBN 9789027233523
}

\section{Olaf Koeneman}

Received: 7 July 2006 / Accepted: 8 August 2006 / Published online: 20 July 2007

(C) Springer Science + Business Media B.V. 2007

\section{Introduction}

In an attempt to simplify reality, one could state that there are two types of linguistic monographs. One type makes an overarching new claim about a particular aspect of the grammar and provides evidence to the best of its ability. The other type approaches the same aspect by going through the existing literature in detail and making a coherent selection of claims from the theoretical proposals on offer. The evidence for this selection is then largely the cumulative evidence provided by the original proposals. Although the second, compromising approach runs the risk of not saying much, it is easy to find very successful examples. Sten Vikner's (1995) monograph, for instance, can be regarded as the definitive proposal on Germanic verb movement and expletives within Government and Binding theory.

Within such a simplified reality, Sabine Mohr's monograph can be regarded as an updated Vikner (1995). She analyzes clausal word order patterns and the distribution of expletives in Germanic by adopting the minimalist programme (Chomsky 1995), with checking theory as an important theoretical component. An important question for the field, of course, is whether empirical progress has been obtained by the change of framework (under the assumption that everybody will agree that at least some conceptual progress has been achieved). Although a comparison is tempting, I will not be able to draw a firm conclusion for a number of reasons. First of all, it would be unfair if not ridiculous, to the frameworks and to the authors, to put the burden of proof on just these two monographs. Second, we should make a distinction between inherent differences between the two frameworks and differences between assumptions made within these frameworks, which is not always easy. If progress is obtained through an hypothesis in the new framework that could in principle have

O. Koeneman $(\bowtie)$

Meertens Instituut, Joan Muyskenweg 25, 1096CJ, Utrecht, The Netherlands

e-mail: olaf.koeneman@meertens.knaw.nl 
been adopted in the old framework as well, then this merely shows the virtue of the new hypothesis but not the virtue of the paradigmatic change. Third, since we are right in the middle of building a new framework and determining what exactly should be part and parcel of it, a comparison may be premature.

Vikner's and Mohr's books are comparative in nature. No matter how minimal (ist) we want our theory to be, when language variation is taken into account, something's got to give. And if we can no longer toy around with definitions of 'government', parametrize directionality or what counts as a 'proper governor', there are still quite a few alternatives. Mohr for instance parametrizes (i) the presence of particular projections, (ii) the location of a feature triggering a particular movement, (iii) whether or not a remnant category is pied-piped by a moving category, (iv) the location at which an element is merged into the structure, and (v) the feature make-up of lexical items. There is nothing wrong with exploring any or all of these options, although eventually we would like the possibilities of parametrization to be more limited. However, at least one attempt to capture existing variation under just one heading, namely feature strength, has proven shallow and uninsightful, so that we are still removed from the ideal. Although in her introduction Mohr portrays minimalism as more flexible than GB-theory, and hence more equipped to account for variation, this may be more true for structure building operations (X-bar theory versus bare phrase structure) than for ways of encoding parametrization. After all, options (i) through (v) can be straightforwardly implemented in GB-theory.

In essence, then, Mohr's monograph is more 'modern' than Vikner's, making use of recently developed hypotheses. The formulation of these hypotheses does not always require a minimalist base, even though minimalist thinking may have inspired their invention. Rather than trying to draw conclusions about frameworks, it therefore makes more sense to look closely at Mohr's ideas and see what questions it conjures up.

The monograph basically consists of two parts. The first part deals with clausal architecture and provides an account of word order differences within the Germanic language group. The focus is on subjects and concomitant positions in the left periphery. The second part deals with a number of impersonal constructions and tries to account for differences between types of impersonal constructions, as well as with cross-linguistic differences in (ostensibly) similar construction types. I will discuss each part in turn.

\section{Clausal architecture and the EPP}

The first part of the book, dealing with basic clausal word order patterns, comprises two subparts. In the first, Mohr presents an overview of the literature and on the basis of this she makes explicit a series of assumptions. In the second part, the word order patterns of the Germanic languages are analyzed, focusing on movements related to subject positions.

\subsection{The EPP deconstructed}

Mohr starts out with a useful overview of how the subject position has been looked at throughout the years and how scholars have thought about the obligatory presence of a subject in the clause. The latter restriction is often referred to as the Extended Projection Principle (EPP) and its formulation has changed over time. The EPP has 
been turned from a principle into a feature. Specific developments in syntax have forced us to rethink the EPP or be more specific about it. The proliferation of structure initiated by Pollock (1989), Rizzi (1997), Cinque (1999), and others has increased the number of positions associated with subjecthood. This at least raises the question of which projection is associated with an EPP-feature triggering the presence of a subject, and why.

Although Mohr does not state it as such, she essentially deconstructs the EPP into two components. One has to do with the obligatory filling of a specifier to satisfy a universal principle, the Extension Condition (Chomsky 1995). The result of this rule is that a specifier must be created after head movement but, as we will see, not always. The other component has to do with the obligatory filling of some specifier, but which specifier exactly is determined by a parameter. The result is that either a specifier in the I-domain (in her analysis SpecTP) or a specifier in the C-domain (in her analysis SpecFinP) is filled. This latter component is inspired by Roberts and Roussou's (2002) generalized EPP-approach, in which the 'classical' EPP (concerning the filling of a position in the I-domain) and verb second (concerning the filling of a position in the C-domain) are part of one and the same parameter. Let us first see what role each component plays and then in Section 3 turn to the actual analysis of word order differences.

As is well known, head movement and XP-movement have different properties, at least under their standard analyses. XP-movement extends the root of the tree. The dotted line in (1b) extends the root of the clause (indicated by the bold-faced line) and therefore makes the tree larger. Head movement does not lead to a tree extension but only makes the tree wider: The dotted line in (1a) does not extend the bold-faced line. Hence, head-movement violates the so-called Extension Condition.

a.

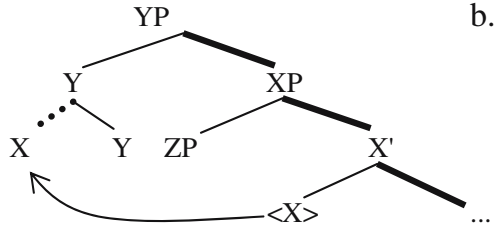

HEAD MOVEMENT

b.

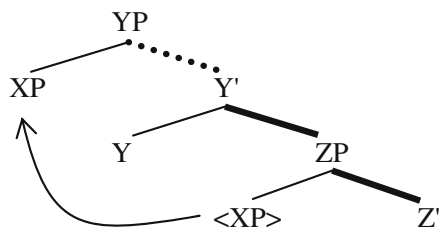

XP-MOVEMENT

Mohr uses this property of head movement to account for the traditional EPP phenomenon. She proposes that evaluation of the Extension Condition does not take place after head movement if some feature on $\mathrm{Y}$ has not been checked yet. This is stated in (2) (p. 50):

\section{The New Extension Condition:}

A given category $\mathrm{C}$ is $\mathrm{EC}$-compatible iff $\mathrm{C}$ is extended at the root once all $\mathrm{F}_{\mathrm{C}}$, formal features of $\mathrm{C}$ (including semantic features, such as Foc, Top, and subject-of-predication) entering into checking operations, are checked. 
If YP in (1a) is TP, V-to-T movement does not extend the tree. Fortunately, there will usually be an unchecked feature on T not checked by the moved verb, namely nominative case. This feature triggers movement of a nominative DP to SpecTP. At that point, all features of category $\mathrm{T}$ are checked and the New Extension Condition becomes relevant. As the last movement, DP to SpecTP, does not violate (2), this XP-movement rescues the structure. Note that Mohr does not attempt to erase the conceptual difference between head movement and XP-movement. On the contrary, this conceptual quirk is what she exploits. This means that the conceptual problem by necessity remains unresolved, a point also made by Andrew Carnie in his review on the Linguist List (July 7, 2006).

The second component of the deconstructed EPP makes use of the suggestion by Roberts and Roussou (2002) that the obligatory presence of a subject in the Idomain and verb second are somehow related. Mohr postulates that there exists a subject of predication feature (sop-feature) and that by means of parametrization this feature resides either in T or Fin. If it is on T, some XP has to move to SpecTP. As $\mathrm{T}$ also contains a nominative feature, this XP will normally be a subject-DP. If the sop-feature is on Fin, some XP must move to SpecFinP. As Fin contains no case feature, any XP can move to that position. Relating two distinct phenomena by means of one parameter is an interesting way of formalizing the intuition that clauses encode 'predicational' relations on different levels: a pure predication relation in the I-domain and a theme-rheme relation in the $\mathrm{C}$-domain. One of the open questions in this approach is whether 'predication', even in a loose sense, is able to capture the relevant properties of the elements residing in the $\mathrm{C}$-domain. After all, a verb second clause can start with an adverb like 'actually' or 'nevertheless'. It is unclear what it means to say that these XPs are predicated over, or that they introduce the 'aboutness' of a clause. They rather act as discursive elements, tightening the link to previous discourse. In this respect, it is not obvious that their presence in the $\mathrm{C}$-domain can or should be regulated by a clause-internal 'predication' requirement.

\subsection{Analyzing clausal word order differences in Germanic}

In an era in which proliferation of functional structure is still very much alive and every syntactician has his/her own favourite projections, a monograph on Germanic word order could in principle be content with assuming a particular cartography on page one and relate the word order differences to it. However, Mohr does a good job of going over the literature and the central arguments in a way that, on the one hand, gives her choices some substance and, on the other hand, still keeps her away from deep and muddy waters. Although one could have discussions about particular assumptions (e.g., does a flexible subject-adverb order really show two subject positions or two adverb positions?), the author can be excused from not going into these methodological issues. What she ends up assuming is that there are a number of positions available to subjects. One is within the V-domain and is thematic in nature. There are two subject positions within the I-domain, SpecTP and SpecRefP, where the latter is reserved for specific subjects. Then there are two in the C-domain, SpecFinP and SpecTopP/FocP. Mohr assumes that DPs, adverbs, PPs, and remnant VPs can move to SpecTopP/SpecFocP if they are semantically triggered. Subjects, nominative or dative, or adverbs that create a 
setting and appear in clause-initial position with neutral stress and interpretation, reside in SpecFinP. The order of projections is basically as in $(3)^{1}$ :

$$
\text { Top/FocP }>\text { FinP }>\text { RefP }>\text { TP }>v P>V P
$$

In her analysis of cross-linguistic differences, Mohr's strategy is a familiar and strong one: the syntax works more or less uniformly in all languages and whenever some language deviates from the expected pattern, some language-particular factor is responsible for that. Let us start by looking at her analysis of the difference between $\mathrm{OV}$ and VO. Mohr assumes that all Germanic languages are underlyingly identical. Contrary to Kayne (1994), an OV order, with the object in SpecVP, is taken to be basic. $\mathrm{VO}$ is then derived through short movement of $\mathrm{V}$ to $v:^{2}$

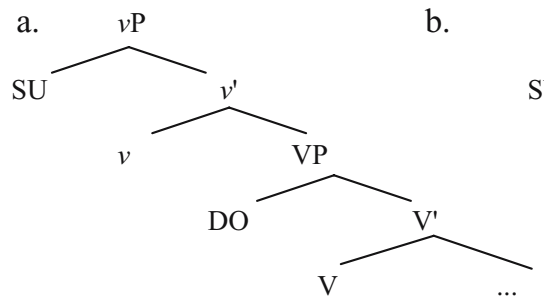

AN OV LANGUAGE

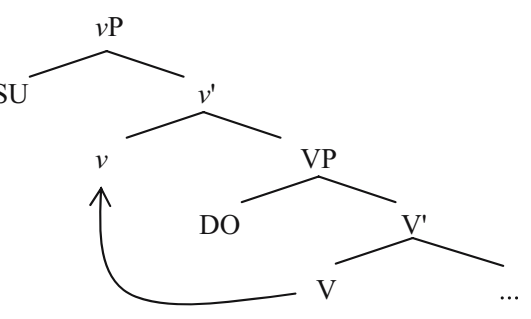

A VO LANGUAGE

V-to- $v$ movement takes place if the verb needs to be licensed. As subject agreement in English is poor, the verb is hardly recognizable as a verb and it therefore needs to be licensed by V-to- $v$ movement. Hence, English is VO at the surface. This proposal raises a couple of issues.

From a conceptual point of view one would like to know what verb licensing means. What is it about V-to- $v$ movement that reveals that the verb is a verb? Mohr suggests that the answer lies in a decomposition approach to lexical items along the lines of Hale and Keyser (1993). Under the assumption that roots can be non-verbal and that little $v$ has the categorial feature $[+\mathrm{V}]$, movement of the root to $v$ will ensure that the resulting entity is a verb. This approach, then, would need to deny that verbal roots exist. Although in line with some current thinking, such a claim is not uncontroversial. Kiparsky (1997), for instance, argues for the existence of nonderived verbs in English. Don (1993, 2005) shows that regularities in conversion processes in Dutch strongly suggest the availability of both verbal and nominal roots.

\footnotetext{
${ }^{1}$ Elements in FinP can move on to TopP if they are semantically triggered. This means that TopP and FinP are never filled at the same time. Please note that I simplify the structure a bit here. In addition to (3), Topic and Focus projections can occur in the I- and V-domain alike if required, but I will mostly abstract away from these.

2 The idea of OV as a universal base order with short verb movement leading to VO has also been put forward by Barbiers $(1998,2000)$, who does not appear in the references.
} 
Second, empirically it becomes important to check the typological literature, as every inflection-less language that is OV will now have to be reasoned away. In fact, the prediction that VO languages should be poorly inflected and OV languages richly inflected is already problematic for the Germanic languages. Dutch, for instance, has three distinctions in the present tense. This must qualify as rich, because Dutch is OV. However, Faroese has three distinctions, yet is VO. English itself turns out to be a problem, too. This language switches from an OV to a VO order in the Old English period (cf. Bean 1983; Lightfoot 1991). Throughout the entire Middle English period, the inflectional paradigm does not change much and consists of three forms in the singular and an overt plural form identical to the infinitive (cf. Haeberli 2002). In the Early Modern English period, there are still three distinctions in the agreement paradigm, of which two are overt (cf. Rohrbacher 1994), which makes it formally identical to the paradigm of Dutch. It seems, then, that the proposal leaves a few centuries unaccounted for. ${ }^{3}$ Although Mohr does not notice this problem, she does discuss another problematic case: Icelandic has five distinctions, yet is VO. She argues that in this language agreement is so rich that it is generated separately from the verbal stem, agreement morphology in $\mathrm{T}$ and participial morphology in $v$. As the verbal stem in $\mathrm{V}$ is bare, it has to be licensed in $v$ and the VO order follows. This, however, leaves unexplained why German (also five distinctions) is OV. Although Mohr is aware of this and suggests that the presence of rich nominal inflection in Icelandic might make the difference, the next problem emerges at the other extreme: Afrikaans has no inflection, yet is OV. For this language, she suggests that the geprefix on a participle identifies the verb as a verb, so that V-to- $v$ movement is redundant and an OV order results.

Mohr's suggestion for Afrikaans highlights a third issue. Not only does the analysis leave the position of inflection-less infinitives in Afrikaans unaccounted for, it is a bit arbitrary as it stands. One would at least like to know why participial and/or infinitival morphology in any of the VO languages does not license the verb and, as a matter of principle, why third person $-s$ in English would not suffice. Although exploring language-specific properties and shifting questions may provide new insights here, for the moment I am inclined to believe that there is a much simpler generalization: there is no correlation between the OV/VO difference and richness of inflection.

These remarks, of course, are no reason to reject the structural part of the analysis. After all, there could be another trigger for verb movement.

As a second step, Mohr argues that the difference between a VO or OV order within $v \mathrm{P}$ has significant consequences for the way the derivation proceeds, which in a crucial way involves SpecTP. In this position, nominative case is checked. There are two ways of doing that, Mohr suggests. One is by moving a nominative DP to this

\footnotetext{
${ }^{3}$ Barbiers (p.c.) suggests that, instead of the loss of person/number marking on the finite verb, the relevant change may have been the disappearance of the infinitival inflection at the beginning of the 15 th century. This hypothesis pushes the date a bit more in the direction of the OV/VO-change but also leads to typological difficulties. The Mainland Scandinavian languages (Swedish, Norwegian, and Danish), for instance, have all become VO but still have overt infinitival endings attached to the verbal stem. 
position (cf. 5a). A second way is to move $v \mathrm{P}$ to that position and allow the head, $\mathrm{T}$, to check features with the specifier of the specifier (cf. 5b), which is the subject-DP.

a.

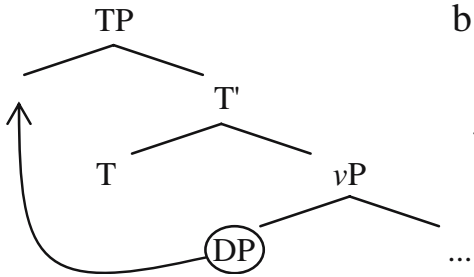

b. $\quad \mathrm{TP}$

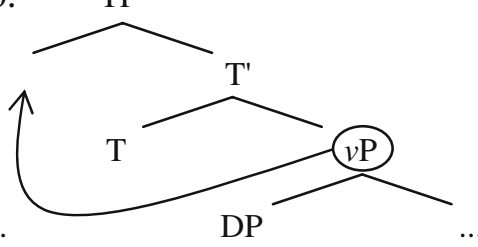

In a way, strategy (5b) is more economical. Looking down into the domain it c-commands, $\mathrm{T}$ will find $v \mathrm{P}$ closer than the specifier of $v \mathrm{P}$ (although it remains a bit unclear how $\mathrm{T}$ can 'see' a nominative feature on $v \mathrm{P}$ ). Now, Mohr proposes that strategy $(5 \mathrm{~b})$ is therefore preferred but that it is only possible if the specifier of $v \mathrm{P}$ is not or no longer in an active checking relation with $\mathrm{V}$ in $v$. Simply put, (5b) is chosen whenever $\mathrm{V}$ is not in $v$.

$\mathrm{V}$ is not in $v$ in either of two cases: (i) when $\mathrm{V}$ does not move to $v$ at all or (ii) when $\mathrm{V}$ has moved through $v$ to a higher position. Let us discuss each scenario, starting with the latter. In all verb second clauses with a simplex tense, the finite verb moves via $v$ and $\mathrm{T}$ to Fin. When it has moved to $\mathrm{T}, \mathrm{V}$ is no longer in an active checking relation with DP in Spec $v \mathrm{P}$, so that the remnant $v \mathrm{P}$ can move to SpecTP, giving the order S-O-V. This is then followed up by verb movement to Fin and XP movement to SpecFinP. Verb second languages are thus similar in main clauses, but they are significantly different in embedded clauses, depending on the OV-VO distinction. In Dutch and German, $[v+\mathrm{V}]$ must move to $\mathrm{T}$ to check for tense and phifeatures in simplex tenses. The remnant $v \mathrm{P}$ subsequently moves to SpecTP and we derive the order S-O-V. After this, a complementizer is merged. In complex tenses, an auxiliary moves to T. Subsequently, $v \mathrm{P}$ is allowed to move to SpecTP, as V does not move to $v$ in Dutch and German. Hence, we derive the order S-O-V-AUX, after which a complementizer is merged. ${ }^{4}$ Mainland Scandinavian (henceforth MSc) languages (Swedish, Norwegian, and Danish) are VO, which means that $\mathrm{V}$ has moved to $v$ to get licensed. For MSc, there is no evidence for further verb movement in embedded clauses. The consequence is that $\mathrm{V}$ is in an active checking relation with the DP-subject, so that this subject rather than $v \mathrm{P}$ moves to SpecTP to check nominative case. The resulting word order is SVO, after which a complementizer is merged. English basically works as embedded clauses in MSc.

Hence, Mohr's system works quite well and captures the basic patterns. There are a few loose ends. Conceptually, it is not completely clear what drives movement. Feature checking, obviously, but there is at least one clear environment where feature checking takes place without movement. In English, as well as in embedded clauses in MSc, the verb occupies $v$. This means that the verb does not move to T to check tense and phifeatures. In the tree structures on page 90, Mohr indicates the existence of an AGREE relation between $\mathrm{T}$ and the verb in $v$. For English, she explicitly states that the little inflection it has "can probably be checked in the spec $v \mathrm{P}-v$ relation or at long distance"

\footnotetext{
${ }^{4}$ This in fact gives the wrong order for Dutch in those constructions with an embedded S-O-AUX-V order, which is a prominent one. Some additional operation must ensure the correct verb cluster order.
} 
(p. 89). However, if these options exist, why does movement occur at all? Or put differently, what makes checking of sop-features different from checking of agreement and tense features? This part of the variation in Germanic is not discussed in much detail.

Second, if a head can check a feature with a specifier of a specifier, the question becomes why this option is not used more often. If in German a subject-DP needs to check a subject-of-predication-feature on Fin, the cheapest option would be to move $v \mathrm{P}$ from SpecTP to SpecFinP, rather than the subject-DP within $v \mathrm{P}$. It then becomes impossible to derive a verb second effect, as the ensuing main clause order would be SOV. In order to circumvent this problem, the theory probably has to be somewhat enriched by a distinction between formal and semantic features and concomitant differences in checking procedures.

A third issue is again typological. Romance languages like Italian and Spanish are richly inflected and have a basic SVO word order. Since these properties are not expected to co-occur, Mohr will probably have to assume what she has assumed for Icelandic: agreement is so rich that it is generated in T. However, we then expect in simplex tenses that V-to-T movement is subsequently followed by movement of $v \mathrm{P}$ to SpecTP, as in Icelandic. The ensuing word order, SOV, is destroyed in Icelandic by the verb second rule. However, Spanish and Italian lack verb second, so that we are stuck with the wrong word order. It would therefore be interesting to see if and how the proposal can be extended to these languages. Focusing on the status of agreement affixes in these languages, perhaps by analyzing them as case-checkers (Sabine Mohr, p.c.), could be a potential avenue.

As these issues do not arise in a more traditional analysis without $v \mathrm{P}-$-movement, one may wonder why Mohr wants to do it this way. The answer is the attempt to derive two generalizations. One generalization is that there are no VO languages in which the auxiliary appears clause-finally, that is, languages that generate clauses such as "John entered the room has" (Holmberg 2000). The other is what is known as Holmberg's generalization, which basically says that in VO languages object movement to the Mittelfeld (shown by crossing of the negation in (6a)) is only possible if the lexical verb moves to a higher position (Holmberg 1986). If the verb stays within $v \mathrm{P}$, as in embedded clauses (6b) and in complex tenses (6c), object shift is ruled out.

a. Jag kysste henne $_{\mathrm{i}}$ inte $\mathrm{t}_{\mathrm{j}} \mathrm{t}_{\mathrm{i}}$.
I kissed her not
'I did not kiss her.'
b. $\quad$ 'Det är troligt att de den ${\text { läste } \mathrm{t}_{\mathrm{i}} .}^{\text {It is probable that they it read-past }}$
'It is probable that they read it.'
*. Jag har henne inte kysst $\mathrm{t}_{\mathrm{i}}$.
I have her not kissed
'I have not kissed her.'

(Swedish)

Let us see how Mohr derives these generalizations. The impossibility of V-O-AUX follows because movement to $\mathrm{T}$ by an auxiliary cannot be followed by movement of $v \mathrm{P}$ to SpecTP if V is in $v$. As in Mohr's analysis the VO word order is indicative of the $\mathrm{V}$ being in $v$, V-O-AUX is correctly ruled out. Holmberg's generalization is derived by analyzing object shift as a case of $v \mathrm{P}$ movement. In a $\mathrm{VO}$ language, $v \mathrm{P}$ containing the 
subject and the object can be moved to SpecTP, thereby crossing a VP-external adverb/negation, but only if the verb has moved out of $v \mathrm{P}$ first: in other words, verb movement feeds $v \mathrm{P}$-movement. If the verb does not move, as in embedded clauses and complex tenses, $v \mathrm{P}$ movement never takes place and we observe no object shift.

These results are interesting. There is, however, one issue that remains unclear. It seems that if the verb moves to Fin, as in verb second clauses, Mohr's analysis predicts object shift all the time, as $v \mathrm{P}$-movement to SpecTP is simply the cheapest way to check nominative on T. However, this is not what we observe. Whether or not the object appears on the left of adverbs/negation depends on properties of the object-DP, too. In MSc, for instance, only pronominal objects can shift, not full DPs (cf. (7)). In Icelandic, full DPs can shift but only when they express old information, usually definite DPs (cf. (8a)). Indefinite object-DPs are found following the adverb (cf. (8b)). Examples are from Holmberg (1999).

a. Hvorfor lœste Peter den ikke?

(Danish)

why read Peter it not

'Why did Peter not read it?'

b. *Hvorfor lœste Peter bogen ikke?

why read Peter book.the not

'Why did Peter not read the book?'

a. Ég les flessar bækur aldrei.

(Icelandic)

I read these books never

'I never read these books.'

b. Ég les aldrei nyjar bækur.

I read never new books

'I never read new books.'

Hence, a remaining question is how Mohr derives constructions in which objects appear to the right of adverbs/negation. In a footnote (p. 91, fn. 101), she suggests that in these cases the object-DPs "have to move out of $v \mathrm{P}$ to some focus position before remnant $v \mathrm{P}$ movement to SpecTP takes place". As long as this focus projection is between $\mathrm{TP}$ and $v \mathrm{P}$, this derivation would capture (8b) but not (7b), as there is no reason why a full DP in $v \mathrm{P}$ could not be piedpiped to SpecTP in MSc. Moreover, a serious word order problem arises for embedded clauses in MSc. In simple tenses, V moves to $v$ and stays there: it does not move on to T. Hence, if an object-DP moves to a $v$ P-external focus projection and the subject-DP to SpecTP, the resulting word order is S-O-V. In complex tenses, the word order would be S-O-AUX-V. Hence, Holmberg's Generalization is captured, but at the cost of unwanted word orders. In order to ensure that the verb precedes the object in SpecFocP, one could postulate some short verb movement to a position between T and Foc. Such a verb movement, however, would in turn feed $v \mathrm{P}$ movement to SpecTP and we would derive S-O-V orders for constructions in which objects do not move to SpecFocP. Hence, some order preserving rule pertaining to the verb and object is additionally needed in 
Mohr's analysis, the nature of which is unclear. But if such a rule is independently needed, the benefits of the $v \mathrm{P}$-movement analysis of object shift become obscure.

\section{Impersonal constructions and subject positions}

In the second part of her book, Mohr looks at a number of impersonal constructions involving expletives and other elements without a clear semantics. What can be observed is that languages may have or lack certain constructions and that ostensibly similar constructions can show important cross-linguistic differences. She rejects analyses in which there is a universal position in which expletives are merged (Vikner 1995) and analyses in which cross-linguistic differences fall out from the number of subject positions available in a language (Bobaljik and Jonas 1996). In addition, she assumes that empty expletives do not exist.

The basic hypothesis is that the variation found follows from the claims about clausal structure made in part one of the book in combination with the hypothesis that a crucial part of the variation is due to the lexical properties of the expletive(-like) elements involved. She distinguishes three types of 'expletives': (i) event arguments, as er in Dutch and $d a$ in German; (ii) quasi-arguments, like English it, which we find with weather predicates; and (iii) true expletives, such as Icelandic pad. Although this distinction in three types is not new, the way Mohr analyzes them and their exact distribution over languages and constructions is. Let us first look at the distinction between expletives and event arguments (Section 3.1) and then at quasi-arguments (Section 3.2).

\subsection{Expletives versus event arguments}

According to Mohr, true expletives are basically featureless, therefore semantically empty, and their only purpose is to check the subject-of-predication feature as a last resort option. As a consequence, Mohr reasons, Dutch er cannot be a true expletive for two reasons. It can occur clause-internally. If the sop-feature in Dutch is on Fin, we expect a real expletive to be merged in SpecFinP and only to occur clause-initially. Second, the presence of er affects the meaning of a clause. This is shown in (9):

$$
\text { De voorstelling kwam maar heel stroef op gang. }
$$

the show came only very slowly on going

'The show had difficulty taking off.'

a. Maar op het laatst werd gelachen.

but on the last was laughed

'But in the end the audience laughed.'

b. Maar op het laatst werd er gelachen.

but on the last was there laughed

'But in the end there were some people who laughed.'

As can be concluded from the English paraphrases, Mohr suggests that the clause without er (cf. (9a)) conveys that a contextually inferable entity laughed, namely the 
audience. The clause with er (cf. (9b)) conveys that a subset of the audience laughed. This contrast can be reproduced for German $d a$ (cf. (10b)) but not for German es (cf. (10a)):

a. *Aber letztendlich wurde es doch gelacht. (German)
but in.the.end was expl after.all laughed
'But in the end there were some people who laughed.'
b. Aber letztendlich wurde da doch gelacht.
but in.the.end was DA after.all laughed

'But in the end there were some people who laughed.'

Mohr proposes the following analysis. $E r$ and $d a$ are event arguments, denoting an abstract 'here and now', and marked [+specific]. As a consequence, they are merged in SpecRefP, also the landing site of specific subjects (cf. example (3) for the clausal structure adopted). What follows from this is that $d a$ and er can occur clauseinternally, namely in specRefP following the verb in Fin. Second, a DP-subject, if present, must be indefinite as it cannot move to specRefP. In other words, er and $d a$ trigger a definiteness effect on the subject (cf. Reuland and ter Meulen 1987). This can be seen in (11).

(11) a. *Er heeft zo-even de kanselier het toneel betreden. expl has just the chancellor the platform entered

'The chancellor has just entered the stage.'

b. *Da hat der Ministerpräsident eine mitreißende Rede gehalten DA has the prime.minister a rousing speech held

(Example (11b) is out if $d a$ is not interpreted as a locational adverb or a particle that marks illocutionary force, basically expressing appreciation.) German es, on the other hand, is a true expletive checking the sop-feature, which in German is on Fin. What follows is that es can only occur clause-initially (hence (10a) is ruled out) and that specRefP is left empty. As a consequence, there is no definiteness effect on a DP-subject, if present, because it can move to SpecRefP.

$$
\begin{aligned}
& \text { Es hat soeben der Kanzler die Bühne betreten. } \\
& \text { expl has just the chancellor the platform entered } \\
& \text { 'The chancellor has just entered the stage.' }
\end{aligned}
$$

The featural makeup of the elements involved is thus responsible for their distribution and for the presence or absence of a definiteness effect on the subject. Two differences are related to one featural difference, an elegant result. As indicated by (9) and (10), there is a third difference pertaining to the semantic contribution of event arguments. Although this aspect of the analysis does not directly affect the result achieved, which 
hinges on the feature $[ \pm$ specific], it could probably be improved. It is not really clear why [+specific] elements should trigger a 'subset reading'. notes, not all Dutch speakers get the contrast in (9). Sjef Barbiers (p.c.) informs me that for him (9a) is ungrammatical and (9b) can be used in both contexts. Personally, I do feel the difference that Mohr is referring to. Nevertheless, (9a) is not ungrammatical for me if a subset of the audience laughed, nor is (9b) when the whole audience laughed. We may be dealing with a pragmatic preference rather than with a semantic difference. If $e r$ is endowed with a specific semantics, we expect it to also trigger a subset reading in clauses with an expressed subject. Take example (13):

$$
\begin{aligned}
& \text { Gisteren heeft (er) niemand gebeld. } \\
& \text { Yesterday has there nobody called } \\
& \text { 'Yesterday, nobody called.' }
\end{aligned}
$$

There is no obvious way, it seems to me, in which insertion of er triggers a subset reading in this case. If anything, I would use the clause without er to convey that there is a presupposed set out of which nobody called, which in a way is the opposite of what Mohr would expect. As the facts are so unclear, an analysis of them seems premature.

Although the idea of a dichotomy between es on the one hand and $d a$ and er on the other is convincing, there is one caveat in the analysis. If es is a pure expletive, inserted to check the sop-feature on Fin, we correctly expect that es cannot show up in embedded clauses:

$$
\begin{aligned}
& \text { *dass es getanzt wurde } \\
& \text { that expl danced was } \\
& \text { '...that there was dancing' }
\end{aligned}
$$

\section{(German)}

However, the impossibility of es in embedded clauses reveals a significant problem. In German, the sop-feature resides in Fin. Hence, this language has an EPP-effect in the C-domain, explaining its verb second property. The quality of this explanation is made to suffer from embedded clauses. As Mohr puts it in a footnote, "The question of where and how the subject-of-predication feature is checked in embedded clauses remains to be solved" (p. 140). If it were possible to insert the sop-feature in a position lower than Fin, we would incorrectly predict that es could show up clause-internally and that (14) would be grammatical. Hence, unification of

\footnotetext{
${ }^{5}$ Mohr notes that the implicit agent is not necessarily indefinite. Take example (i).
}

(i) Er werd door iedereen gedanst.

(Dutch)

Expl was by everyone danced

'Everyone was dancing.'

Here the implicit agent, realized in a door-('by'-)phrase, is not an indefinite and the result is perfect, which is unexpected by the analysis. Mohr therefore assumes that er might trigger a sub-event reading. Although it is hard to test this claim, note that it would also remain unclear how a [+specific] feature on er would trigger such a reading. 
verb second and the classical EPP-effect in the I-domain comes at the cost of not understanding asymmetric verb second languages. A competing, more standard analysis that takes the EPP-effect to be restricted to the I-domain (e.g., Vikner's analysis) and es to be a topic-expletive (cf. Tomaselli 1990) derives the root/non-root asymmetry and the distribution of es straightforwardly. Verb second would then have to be analyzed as something additional, but this competing analysis can, at least for the time being, simply use asymmetric verb second languages as an argument against unification.

The difference between expletives and event arguments dictates the analysis of the other Germanic languages. Let us look at MSc, Icelandic, and English in turn.

In Norwegian and Swedish, the element det can show up clause-internally (see (15a)), which means it cannot be a true expletive. It cannot co-occur with a subject (MSc does not have so-called transitive expletive constructions, see (15b)). Third, it triggers a definiteness effect on the object (see (15c)).
a. I går ble det danset.
(Norwegian)
yesterday was expl danced
'Yesterday, there was dancing/People were dancing.'
b. *Det har någon ätit ett äpple.
expl has someone eaten an apple
(Swedish)
'Someone has eaten an apple.'
c. *...at det ble spist eplet
(Norwegian)
that expl was eaten apple. the
'...that the apple was eaten'

Mohr argues that det is a quasi-argument inserted in SpecvP. What follows is that det cannot co-occur with a subject, as they compete for the same slot. The definiteness effect on the object, which is the logical subject, follows as det is closer to SpecRefP, making it impossible for the logical subject to check its [+specific]-feature there. An attractive feature of this analysis is that, in contrast to er and da, det is of pronominal origin and this difference is played out accordingly. Nevertheless, the idea that det is a quasiargument is an hypothesis not yet supported by independent evidence. One would like to know what kind of thematic properties can be associated with it, or at least see that there must be thematic properties associated with it. This is in general difficult to do. It has for instance been shown for weather-it in English, which has the ability to control PRO:

$$
\text { It rained without PRO stopping. }
$$

This test, however, does not work for German, which lacks a gerund comparable to 'stopping' (Sabine Mohr, p.c.).

The analysis of det as a quasi-argument raises a problem for English. If quasiarguments can be generated vP-internally in the absence of a clear thematic role, why is this option not used in English? That is, what now excludes (17)?

*It was danced.

This shows the general analytical trade-off for research into impersonal constructions: Either we stick to the hypothesis that quasi-arguments are recognizable as such due to 
their pronominal original and (17) becomes problematic, or we drop this hypothesis, despite its appeal, and analyze det as an expletive. This is not a step that Mohr is willing to take for independent reasons. As expletives are sop-feature checkers, generated high in the structure, her explanation for the paradigm in (15) would be lost.

As Icelandic pað can only occur clause-initially, it must be a true expletive checking the sop-feature. As expected, pað can co-occur with a subject: Icelandic has transitive expletive constructions. There is one unexpected property: In contrast to German es, Icelandic pað displays a definiteness effect on the subject.

Раð lesa margir stúdentar/*stúdentarnir bækur eftir Chomsky.

there read many students/students.the books by Chomsky

'Many/the students read books by Chomsky.'

Mohr argues that this is a consequence of the fact that in Icelandic a definite subject must be the subject of predication (holding at the level of FinP) and therefore always targets SpecFinP. Hence, definite subjects and expletives cannot co-occur, as they compete for the same structural slot. Evidence for this behaviour of definite DPs comes from her informant (Gunnar Hrafnbjargarson), who judges topicalization constructions with a definite DP ungrammatical:

\section{*Á lestarstöðina er forsetinn mœttur. at train.station.the is president.the showed.up}

'At the station, the president has shown up.'

The ungrammaticality of (19) may be due to the presentational flavour of this example, triggered by the choice of clause-initial XP. Jóhannes Gísli Jónsson, however, informs me that the problem in (19) is that "the topicalization of the locative phrase is not so good (and it is therefore irrelevant whether the subject is definite or not)". For him, the following examples with a definite subject in third position are all fully grammatical:

a. Í sjónvarpinu er forsetinn yfirleitt brosandi.

On TV is president.the usually smiling

'On TV, the president usually smiles.'

b. Um helgar er forsetinn alltaf í golfi.

On weekends is president.the always playing golf

'During weekends, the president always plays golf.'

c. Petta sjónarmið hafði forsetinn ekki hugsað út í.

This viewpoint had president.the not thought of'

'This viewpoint, the president had not thought of.'

Hence, it seems unlikely that definite DPs and pad necessarily compete for the same slot, so the presence of a definiteness effect in Icelandic remains somewhat of a mystery. ${ }^{6}$

\footnotetext{
${ }^{6}$ Note that one cannot argue that the clause-initial XPs in (20) are in SpecTopP, so that SpecFinP can be used by the definite subjects. If that were possible, we would also expect the possibility of clause-internal pað. In other words, TopP and FinP cannot be both overtly filled in one clause, which can be captured by saying that whatever XP ends up in SpecTopP must move through SpecFinP.

烈 Springer
} 
For English, Mohr treats there-constructions as focus constructions. The presence of there ensures that focus is not on the whole clause but has been narrowed down to the object-DP, which must appear clause-finally (as in heavy NP constructions). As there is not of pronominal origin, Mohr treats it as an event argument. She therefore expects that there can show up in transitive constructions. This appears true, but only partly so. Consider the examples in (21):
a. $\quad *$ There ate <someone $>$ an apple <someone $>$
b. There entered the room a strange man.

What appears to be the case is that there legitimately occurs in a transitive construction if the object is a locative argument. These puzzling facts have often been ignored in analyses of expletive constructions. Mohr finds the following solution. She proposes that there is an event argument that doubles the locative argument in a small clause:

[there [sC DP PP ]]

This construction is generated as the argument of a copular or unaccusative verb. How the derivation proceeds is complicated and not relevant to the discussion here. What follows are two facts. First of all, there cannot occur if there is no locative argument present (overtly or covertly, as in examples like There arrived three men). Hence, the contrast in (21) is accounted for. Second, if there originates in a small clause, there must also be a DP-argument which the locative category predicates over. This argument is crucially lacking in impersonal passives:

*There was danced

Hence, the analysis naturally accounts for the impossibility of such constructions in English.

An alternative way of analyzing (21b) is to view enter the room as a complex unaccusative predicate taking a single argument. It then becomes possible to treat there on a par with MSc det and achieve some unification: Both can occur clauseinternally but neither can occur with a transitive predicate. However, we then lose an explanation for the ungrammaticality of (23). As translations of (23) into Norwegian and Swedish are grammatical, the hypothesis that there and det are distinct elements cannot be rejected so easily, which supports Mohr's strategy.

\subsection{Quasi-arguments}

Mohr largely follows common practice and assumes that expletives in weatherclauses are quasi-arguments that can check nominative case and act as subjects of predication. Hence, she arrives at the typology shown in Table 1.

There are a few instances in which she deviates from standard analyses. I will mention two. 
In Icelandic, no overt element appears in third position and pað, if present, only shows up in clause-initial position:
a. $\quad$ Pað rigndi (í gær).
expl rained yesterday
'It rained yesterday.'
b. *Ígær rigndi pað.
yesterday rained expl
'Yesterday it rained.'

(Icelandic)

Mohr suggests that pad is the regular true expletive checking an sop-feature in the C-domain and that weather-predicates simply select no argument. This means that SpecTP is not present. This does not lead to a violation of the Extension Condition. Recall that Mohr, for independent reasons, assumed that in Icelandic inflection is merged in T. Under the assumption that this inflection does all the checking, the Extension Condition is consulted after merger of inflection, an operation which is tree extending. Subsequent verb movement only takes place for phonological reasons and not for feature checking purposes. Hence, no specifier needs to be created. Mohr provides additional evidence for the hypothesis that weatherpredicates lack an argument in Icelandic. Sentences like (16) cannot be translated into Icelandic, which suggests there is no argument to control the implicit subject in the without-clause. Here, Mohr's assumptions from the first part of the book pay off.

The section on Yiddish contains new data, at least to me. She observes that es readily occurs in clause-initial position, which is analyzed on a par with Icelandic. Es, however, also appears in clause-internal position, but gives marginal results:

$$
\begin{aligned}
& \text { ?Haytn regnt es. } \\
& \text { today rains it } \\
& \text { 'Today, it rains.' }
\end{aligned}
$$

Interestingly, this example becomes fully grammatical if an object is added:
Haytn regt es konfeti.
(Yiddish)
today rains it confetti
'Today, it rains confetti.'

Table 1 Entities in impersonal constructions and their properties

\begin{tabular}{lllllll}
\hline & Insertion site & $\begin{array}{l}\text { Clause- } \\
\text { internal }\end{array}$ & $\begin{array}{llllll}\text { Definiteness } \\
\text { effect }\end{array}$ & $\begin{array}{l}\text { Checker of } \\
\text { sop-feature }\end{array}$ & $\begin{array}{l}\text { Feature } \\
\text { make-up }\end{array}$ \\
\hline Expletive & SpecFinP & SpecTP & No & No & Yes & [-Specific] \\
Event argument & SpecRefP & SC-adjunct & Yes & Yes & Yes & [+Specific] \\
Quasi-argument & SpecvP & Spec $v P$ & Yes & Yes & Yes & [+Specific] \\
\hline
\end{tabular}

\footnotetext{
a The analysis of there as a small clause adjunct doubling a locative category is an analysis specific for English, not hinging on the absence of the verb second property.

를 Springer
} 
Mohr proposes that es is a quasi-argument here that has a 'transitivisation' effect on the predicate. Insertion of nominative es makes accusative case available, which subsequently licenses an object.

This transitivisation effect also shows up in the last section of the second part of the monograph, which deals with impersonal psych verbs. Here we find a contrast between Icelandic and German. The former does not allow pað, not even in clauseinitial position, whereas the latter allows es in initial and clause-internal positions.

a. *раð er mér kalt.

(Icelandic)

expl/it is me dat cold

'I feel cold.'

b. *Mér er pað kalt.

$m_{\text {dat }}$ is expl/it cold

'I feel cold.'

(28)
a. Mir ist's kalt.
$m_{\text {dat }}$ is it cold
'I feel cold.'
b. ?(E)s ist mir kalt.
it is me dat cold
'I feel cold.'

(German)

The dative (or accusative) argument in Icelandic is analyzed as the real subject, which checks the sop-feature by moving to SpecFinP. Mohr suggests that for this reason there is no need for pað. In German, the dative argument is not a real subject (it fails the tests for subjecthood in Zaenen et al. 1985). Hence, there is room for a quasi-argument in Spec $\mathrm{P}$, es. In impersonal psych constructions, es can also remain absent but this gives a degraded result if the internal argument is accusative rather than dative.
a. $\quad$...weil mir kalt ist
because me dat $_{\text {cold }}$ is
'because I feel cold'
b. ?...weil mich friert
because me acc $_{\text {freezes }}$
'because I feel cold'

(German)

Dative is an inherent case in German, Mohr reasons, but to have a legitimate accusative object es must be present. Again, we find a 'transitivisation' effect due to es. 
As it turns out, the examples in (29) bear on the core of Mohr's monograph. Note that for these clauses without es, the question is what rescues a potential violation of the Extension Condition after the finite verb has moved to T. $v \mathrm{P}$ is allowed to move to SpecTP, but there is no nominative case feature to trigger this movement. Hence, Mohr is forced to assume a strictly formal EPP-feature here. A similar solution must be used to account for the obligatory clause-internal presence of der in Danish:

...at der er blevet danset

(Danish)

that expl is been danced

'that there has been dancing'

As der is not of pronominal origin, it cannot check nominative case. As Danish is a verb second language, the sop-feature resides in Fin. Danish has no verb movement to $\mathrm{T}$ in embedded clauses, so no problem arises for the Extension Condition either. As der cannot be merged into the structure for any of these reasons, its presence must again be enforced by the postulation of a purely formal EPPcondition. The fact that we have classical, that is, I-domain related, EPP-effects in verb second languages shows that the EPP cannot be reduced to a parametrized sopfeature (and not to nominative case either, for that matter). Although Mohr comes a long way, a small EPP-residue remains (cf. also the discussion about example (14)). This forces Mohr to ultimately abandon sop-features and fall back on the idea that purely formal EPP-features are inserted to trigger movement, that is, the creation of a specifier. In this sense, traditional EPP-effects and verb second are still unified, but in an ad hoc and uninsightful way: In both cases we observe movement to a specifier and an abstract feature is postulated to trigger exactly this. It is, of course, a rather unfortunate outcome but there is a positive way of looking at it: In her 'failed' attempt to reduce the notion 'EPP' to more contentful sop-features, Mohr identifies in a very precise way what the problem is, namely asymmetric verb second languages.

\section{Conclusion}

Mohr presents a coherent approach to two topics that have received a lot of attention in the literature on Germanic. Her analyses of the phenomena inherent to them are interwoven to a large extent in the sense that assumptions and hypotheses made in part one of the book are taken up and exploited in the second part.

As the literature on Germanic clause structure, verb movement, and the distribution of expletives is large, it is understandable and more and more unavoidable that the choice of literature cited and discussed in monographs is eclectic. For instance, the division of 'expletives' into real expletives, quasiarguments, and what Mohr coins event arguments; the claim that Dutch er resembles German $d a$ rather than es; and the claim that empty expletives should be dispensed with are all properties that Mohr's analysis for instance shares with Koeneman (2000) and Koeneman and Neeleman (2001), which for obvious reasons I would like to have seen in the references. Another example: Bobaljik and Jonas (1996) is 
treated in some detail, but Bobaljik and Thráinsson (1998), is not, although conceptually and empirically superior.

A bit unfortunate, however, is the fact that a comparison of results is scarce at points. With respect to the word order part, an extensive comparison with traditional analyses, as well as with strictly Kaynian VO-approaches, would have been welcome, given the centrality of the claims made. With respect to the impersonal constructions, Bennis' (1986) seminal work on Dutch expletives is, for example, referred to, but it remains unclear to what extent her analysis of er as an event argument can be empirically distinguished from Bennis' claim that it is a presupposition carrier. The particular benefits of Mohr's approach now remain a bit obscure to the reader, who can too easily be left with the feeling that Mohr basically presents another way of doing things.

There is one point in the discussion where Mohr's analysis can be straightforwardly compared to its predecessors. She discusses Vikner's approach to expletive distribution in some detail, pointing out its shortcomings. The outcome of this comparison, however, is unclear. Mohr explicitly states (p. 123) that "[t]he real problem with Vikner's approach is a conceptual one". Vikner assumes one location of expletive insertion with the consequence that VP-internal subjects must be postulated "all over the place", even in the absence of clear evidence. Although I happen to agree with Mohr on the idea that the location of expletive insertion is to some extent flexible (cf. also Sigurðsson 1989; Tomaselli 1990), some scholars will no doubt find this claim conceptually unattractive. Although I also happen to agree with Mohr that empty expletives should be dispensed with if possible, other scholars will embrace them, as their inclusion makes it possible to achieve-conceptually attractive - uniformity of clause structure. In the end, one cannot win a war with conceptual arguments and some new ground must be conquered. The fact that Mohr's analysis, with a central role played by sop-features, runs into problems with asymmetric verb second languages (cf. the discussion about (10) and (26) previously) is therefore not innocent, and the alternative she must fall back on (in terms of formal EPP-features) shows no clear improvement over traditional or other current analyses.

By making explicit comparisons with other approaches part of the research, and by making explicit the progress achieved, we can potentially judge which part of this progress is due to assumptions that are part and parcel of the framework chosen (here: the minimalist programme) and which part is due to specific assumptions made within this framework. A pervasive idea within the minimalist programme is that variation should be encoded in the lexicon. Mohr partly acts in this spirit, as it is the properties of the 'expletive' elements and the status of verbal agreement that are taken to be responsible for substantial variation in the syntax. Although Mohr achieves specific results with this strategy (which are more convincing in the realm of expletives than in the realm of verb movement), these claims could be, and in fact have been, stated in an old-fashioned framework like Government and Binding Theory as well. As is only fair to expect, the tension between conceptual progress and empirical progress remains unresolved in this monograph, which essentially shows that, independently of the framework chosen, accounting for language variation is a struggle, and a fascinating one. And it is in this struggle that Mohr makes a valid contribution. 
Acknowledgements I would like to thank Sabine Mohr, Marika Lekakou, and Sjef Barbiers for commenting on an earlier version of this review.

\section{References}

Barbiers, S. (1998). English and Dutch as SOV-languages and the distribution of CP-complements. In R. van Bezooijen \& R. Kager (Eds.), Linguistics in The Netherlands (pp. 13-25). Amsterdam: Benjamins.

Barbiers, S. (2000). The right periphery in SOV languages. In P. Svenonius (Ed.), The derivation of VO and $O V$ (pp. 181-218). Amsterdam: Benjamins.

Bean, M. (1983). The development of word order patterns in old English. Totowa, NJ: Barnes \& Noble Books. Bennis, H. (1986). Gaps and dummies. Dordrecht: Foris.

Bobaljik, J. \& Jonas, D. (1996). Subject positions and the roles of TP. Linguistic Inquiry, 27, $195-236$.

Bobaljik, J. \& Thráinsson, H. (1998). Two heads aren’t always better than one. Syntax, 1, 37-71.

Chomsky, N. (1995). The minimalist program. Cambridge, MA: MIT Press.

Cinque, G. (1999). Adverbs and functional heads. Oxford: Oxford University Press.

Don, J. (1993). Morphological conversion. Ph.D. dissertation. The Netherlands: Utrecht University.

Don, J. (2005). Categories in the lexicon. Linguistics, 42, 931-956.

Haeberli, E. (2002). Inflectional morphology and the loss of verb second in English. In D. Lightfoot (Ed.), Syntactic effects of morphological change (pp. 88-106). Oxford: Oxford University Press.

Hale, K. \& Keyser, S. J. (1993). On argument structure and the lexical expression of syntactic relations. In K. Hale \& S. J. Keyser (Eds.), The view from building 20. Essays in linguistics in honor of Sylvain Bromberger (pp. 53-109). Cambridge, MA: MIT Press.

Holmberg, A. (1986). Word order and syntactic features in the Scandinavian languages and English. Ph.D. dissertation. Sweden: University of Stockholm.

Holmberg, A. (1999). Remarks on Holmberg's generalization. Studia Linguistica, 53, 1-39.

Holmberg, A. (2000). Deriving OV order in Finnish. In P. Svenonius (Ed.), The derivation of VO and OV (pp. 123-152). Amsterdam: Benjamins.

Kayne, R. (1994). The antisymmetry of syntax. Cambridge, MA: MIT Press.

Kiparsky, P. (1997). Remarks on denominal verbs. In A. Alsina, J. Bresnan, \& P. Sells (Eds.), Argument structure (pp. 473-499). Stanford: CSLI.

Koeneman, O. (2000). The flexible nature of verb movement. Ph.D. dissertation. The Netherlands: University of Utrecht.

Koeneman, O. \& Neeleman, A. (2001). Predication, verb movement and the distribution of expletives. Lingua, 111, 189-233.

Lightfoot, D. (1991). How to set parameters. Cambridge, MA: MIT Press.

Pollock, J.-Y. (1989). Verb movement, universal grammar, and the structure of IP. Linguistic Inquiry, 20, $365-424$.

Reuland, E. \& ter Meulen, A. (Eds.) (1987) The representation of (in)definiteness. Cambridge: MIT Press.

Rizzi, L. (1997). The fine structure of the left periphery. In L. Haegeman (Ed.), Elements of grammar (pp. 281-337). Dordrecht: Kluwer.

Roberts, I. \& Roussou, A. (2002). The extended projection principle as a condition on the tensedependency. In P. Svenonius (Ed.), Subjects, expletives, and the EPP (pp. 125-155). Oxford: Oxford University Press.

Rohrbacher, B. (1994). The Germanic languages and the full paradigm. Ph.D. dissertation, University of Massachusetts, Amherst.

Sigurðsson, H. (1989). Verbal syntax and case in Icelandic. Ph.D. dissertation. Sweden: University of Lund.

Tomaselli, A. (1990). La sintassi del verbo finito nelle lingue germaniche. Padua: Unipress.

Vikner, S. (1995). Verb movement and expletive subjects in the Germanic languages. Oxford: Oxford University Press.

Zaenen, A., Maling, J., \& Thráinsson, H. (1985). Case and grammatical functions: The Icelandic passive. Natural Language and Linguistic Theory, 3, 441-483. 